\title{
Friction Induced Wear of Rapid Prototyping Generated Materials: A Review
}

\author{
A. Tsouknidas \\ Laboratory for Machine Tools and Manufacturing Engineering, Mechanical Engineering Department, \\ Aristoteles University of Thessaloniki, 54124 Thessaloniki, Greece \\ Correspondence should be addressed to A. Tsouknidas, alextso@auth.gr
}

Received 30 June 2011; Accepted 12 July 2011

Academic Editor: Nikolaos Michailidis

Copyright ( $) 2011$ A. Tsouknidas. This is an open access article distributed under the Creative Commons Attribution License, which permits unrestricted use, distribution, and reproduction in any medium, provided the original work is properly cited.

Additive manufacturing has been introduced in the early $80 \mathrm{~s}$ and has gained importance as a manufacturing process ever since. Even though the inception of the implicated processes predominantly focused on prototyping purposes, during the last years rapid prototyping (RP) has emerged as a key enabling technology for the fabrication of highly customized, functionally gradient materials. This paper reviews friction-related wear phenomena and the corresponding deterioration mechanisms of RP-generated components as well as the potential of improving the implicated materials' wear resistance without significantly altering the process itself. The paper briefly introduces the concept of RP technologies and the implicated materials, as a premises to the processdependent wear progression of the generated components for various degeneration scenarios (dry sliding, fretting, etc.).

\section{Introduction}

Rapid prototyping (RP) poses a promising alternative to conventional manufacturing techniques during concept evaluation, design optimization, rapid tooling, and lately for direct production of customer driven products. The comparative advantages of additive manufacturing are both cost and time related while RP facilitates the direct incorporation of functional characteristics into the final product.

The basic concept of RP techniques relays on the conversion of 3D geometries, generated or processed by computeraided design (CAD), into an STL file format. This is followed by the segmentation of the object in a series of overlaying layers, an essential step in the bottom-up approach of any additive manufacturing process. RP processes initiate with the construction of the objects' base layer and progress upwards, with each layer being deposited/formed on top of the proceeding one, finally resulting in the desired 3D geometry.

This approach circumvents limitations associated with conventional manufacturing methods, provides products with competitive strength characteristics, allows the fabrication of geometries of unequal complexity, while simplifying the incorporation of application specific features into the produced object [1].

Several industrial sectors (automotive, aerospace, and medical) have embraced, supported, and in some cases even dictated recent advances in RP, leading to customized, high added value products, whereas the implicated technologies can be easily extended to numerous other applications.

Rapid prototyping technologies can be categorized into three main categories: solid based like fused deposition modeling (FDM), powder based as selective laser sintering (SLS), and liquid based methods, for example, stereolithography. Further classifications can refer to the processed material (metallic, ceramic, polymer, or composite) as well as the employed bonding/fusing technique.

Several material properties of RP-generated products have to be considered during the proper technique selection [2]. Among these prevails friction-dependent wear, which may be considered a pivotal property of mechanical components utilized in a series of applications where mating surfaces are subjected to sliding.

Friction-based surface degeneration is a major determinant of a mechanical components' longevity, that is, artificial joints [3], implants $[4,5]$, gears [6], bearings [7], seals [8], 
and so forth, are primarily wear dependent, while their wear resistance is also strongly associated with the parts' periodical service requirements.

Hitherto substantial contributions have been made on the current state-of-the art rapid prototyping, manufacturing, and tooling techniques [9-12]. The tribological aspects; however, of RP-produced components have, to the best of the author's knowledge, never been extensively documented.

\section{Methods and Materials}

2.1. RP Technologies. Friction-induced failure is considered an important aspect during the material/process selection of a suiting RP methodology. Furthermore, RP techniques are extensively employed in clean room environments and the medical sector where the release of wear particles and ions is considered a significant sterility problem [13]. Recent advances in RP technologies not only allow the fabrication of components able to withstand conventional sterilization processes but also incorporate gamma-ray sterilization and similar techniques into their systems, allowing the direct commercial production of FDA-approved implants. The release of particles due to friction, during the components function, may arise this issues nonetheless, thus the wear resistance of these techniques has to be thoroughly considered.

There exist a variety of more than 40 different RP technologies, which do, however, bare similar characteristics and are alike in concept. Selective laser sintering (SLS) is an RP technique utilizing a laser beam to fuse small material particles into a 3-dimensional shape. The laser scans a predefined contour on the surface of a powder bed, which is consecutively lowered by a one-layer thickness, only to be covered by the powdered material, which is reapplied on top of the sintered cross-section, as schematically presented in Figure 1. This process is repeated until the complete fabrication of the desired 3D geometry. Virtually any material that can be powdered, plastic, polymer, ceramic, metals or even composites can be fused, employing SLS technologies [14, 15]. The limitations of the method are associated with the thermal properties of the commissioned powder, which must maintain its integrity and not completely decompose once the laser is applied. Selective laser melting (SLM) is a recent alterative to the SLS process, which relies on the complete melting of the powdered materials.

Fused deposition modeling (FDM) is another widely applied RP process $[10,16]$ based on materials exhibiting a low melting point even though harder materials can also be employed [17]. In this context polymers or plastics are utilized as the main material matrix, which can be reinforced, by metallic fibers or ceramic fillers. The final thermosoftening powder is guided through a heated nozzle and deposited through the extrusion head as a partially liquefied (semisolid) wire, as demonstrated in Figure 2. The CNC-controlled nozzle follows the desired tool-path, defined by a specific slice of the CAD file, gradually structuring the desired object.

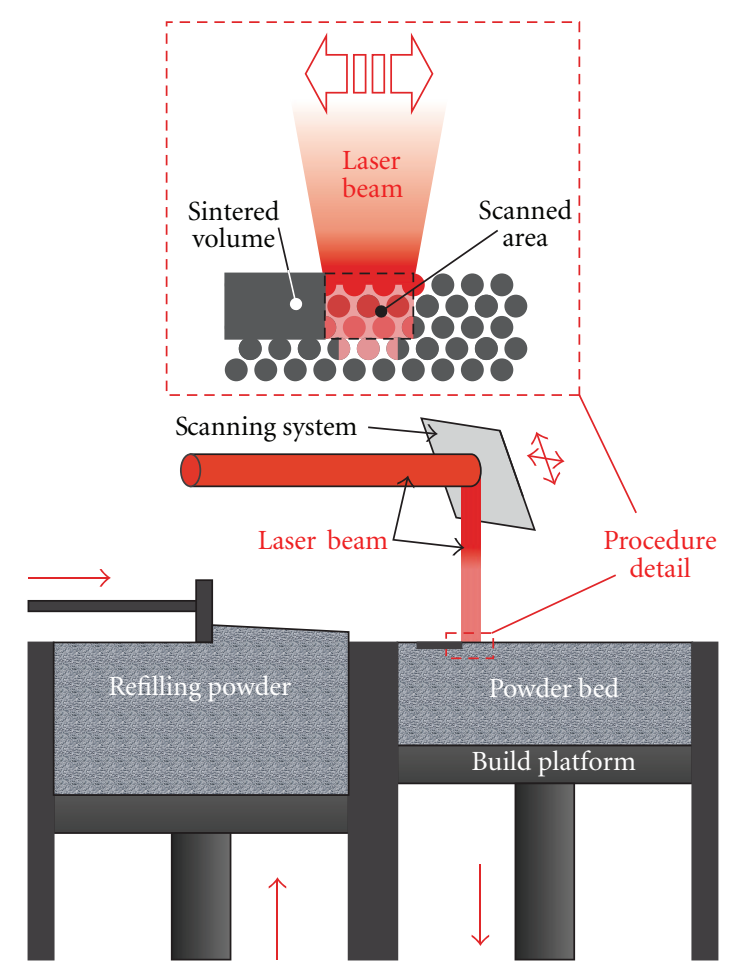

FIGURE 1: Selective laser sintering process.

This review will focus on the wear development and the related wear mechanisms of FDM-produced polymeric and binary polymer-ceramic composites $[18,19]$ as well as SLSand SLM-fabricated metallic parts ranging from stainless and tool steels to Ti and Co alloys $[15,20]$.

2.2. Fretting Wear Test. Fretting wear, refers to the frictionbased interfacial damage of a component pressed against a repetitive tangential vibrating countersurface. This oscillatory motion is usually defined by small displacement amplitudes [21, 22], during which the specimen is fixed and the counter-surface is subjected to a linearly vibrating motion (see Figure 3 ), or vice versa.

The concept of fretting replicates the friction-based wear of a series of RP applications, accurately mimicking their mechanical behavior. Artificial joints, hip implants, and several other RP-fabricated components are especially prone to friction fatigue, drastically reducing their life expectancy $[23,24]$.

Even though fretting results in complex wear mechanisms, there is a consensus throughout literature concerning the existence of three major fretting modes: fretting wear $[25,26]$, fretting fatigue, and fretting corrosion [27].

A dominating phenomenon in fretting is the so-called "third body effect" exerted by the entrapment of material debris within the sliding interface due to the minute relative displacements of the two counterbodies [28]. This material response, provides composites with their exceptional wear properties, as their coefficient of friction drastically alters due to this in situ lubricant effect, exerted by the formation 


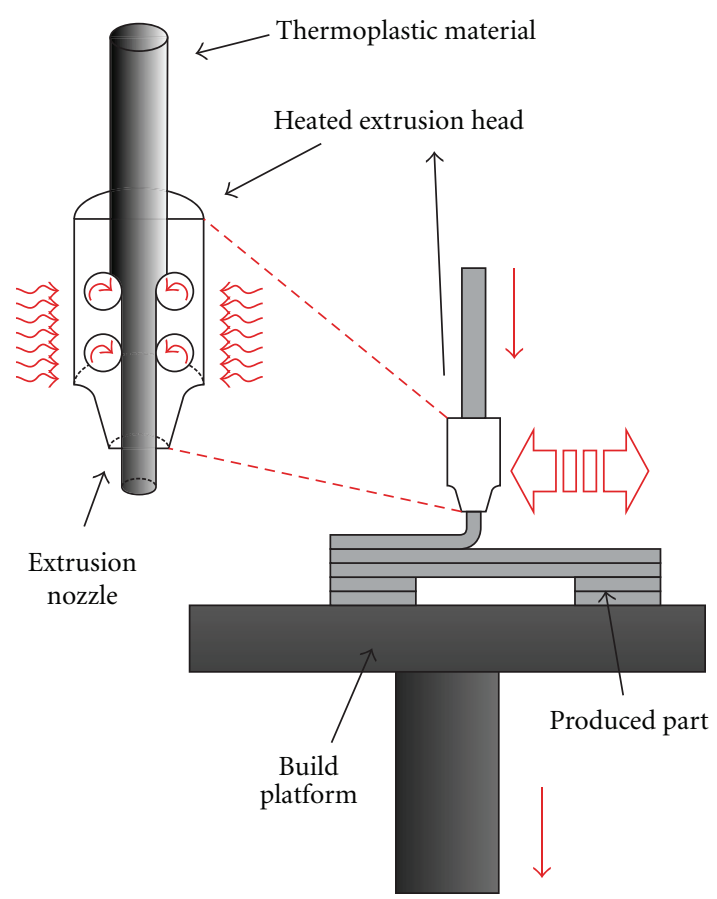

FIGURE 2: Fused deposition modeling process.

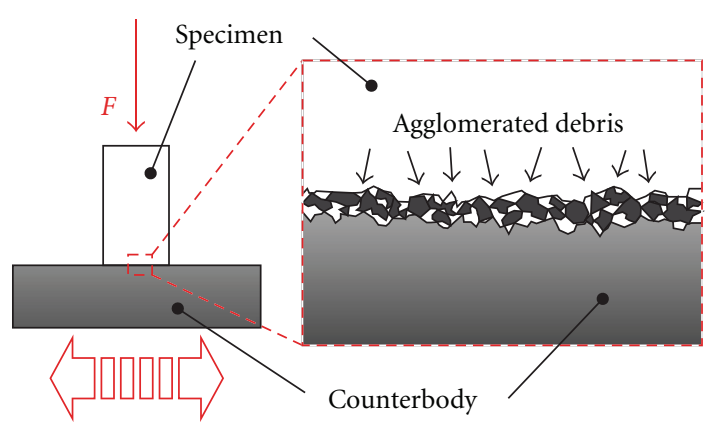

FIGURE 3: Fretting concept - third body effect.

of an inhomogeneous transfer layer mainly consisting of particles with higher wear resistance $[29,30]$.

2.3. Tribometer Friction Tests. The determination of a materials dry sliding wear characteristics is conventionally conducted by means of pin-on-disc (POD) arrangements, as illustrated in Figure 4, and in correspondence to the ASTM G99-04 [31] standard. POD tests are based on a simplified sliding concept, were the accumulation of wear debris is rather insignificant and thermal degeneration less likely to affect the wear progression when compared to fretting.

During POD experiments, a pin-like specimen is pressed against a sliding counter-surface by the application of a dead weight. The counter-surface is usually composed of a metallic disc rotating at a constant velocity and possessing a specific roughness value $(\mathrm{Ra})$, which is considered a critical factor $[32,33]$. The examined specimens must be polished thoroughly (by grit emery paper) to ensure the uniform and axial contact of their surface to the disc and reduce

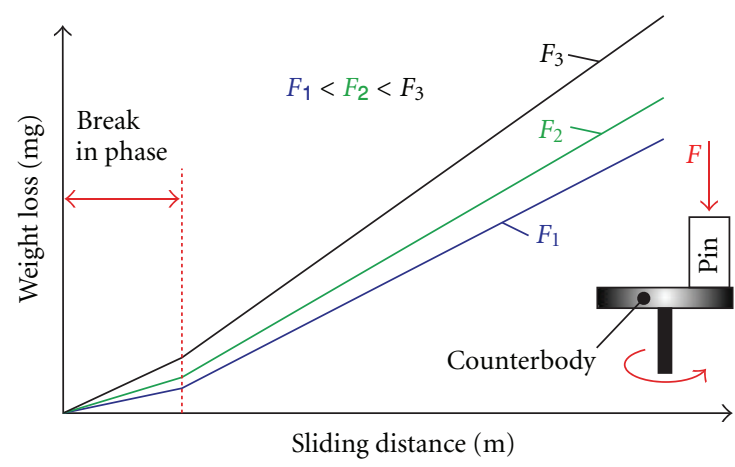

FIgURE 4: Pin-on-disc concept-break in phase.

the so called "break in phase," encountered during the initial sliding period, were foreign materials are removed from the contacting surfaces and a complete contact of the counterbodies is established [18].

\section{Friction and Wear Behavior}

3.1. Effect of the Materials' Strength Properties. Although it would be anticipated that the material strength properties exert a vital role on the wear behavior of the RP-fabricated materials, existing research states otherwise, as presented in Figure 5. It has been documented that $\mathrm{Ti}$ and Co-alloys exhibit increased (by more than two magnitudes) wear rates during fretting when compared to stainless steels, which are far more ductile [15]. The same tendency is observed when comparing SLS/SLM iron-based materials with milled tool steels, which possess higher strength properties, paradoxically the SLS/SLM materials demonstrate superior wear characteristics [15]. Laser sintered Mo-WC MMC's have also been reported to exhibited better abrasive wear resistance when compared to the base metal [34]. Even when compared to conventional sintering, SLS is capable of producing iron-graphite components with substantially different wear properties [35].

A similar material response has been observed in FDMproduced materials, where hardness cannot be considered as an indicator of wear resistance [18].

3.2. Effect of Reinforcement. Even though the material strength properties cannot be directly correlated to the wear resistance of RP-produced components, the enslavement of the materials' wear progression to the presence of a reinforcement phase has been well documented (see Figure 5).

The dispersion of hard particles like silicon carbide within a laser sintered iron matrix has a clear effect on the resulting composite's wear rates during dry sliding, as this results in an increased coefficient of friction. Wear volumes, however, tend to decrease drastically with an augmentation of the w/w\% silicon carbide content [36]. This behavior can be attributed to onset adhesive processes such as scuffing [37] while improving the components wear and seizure resistance. 


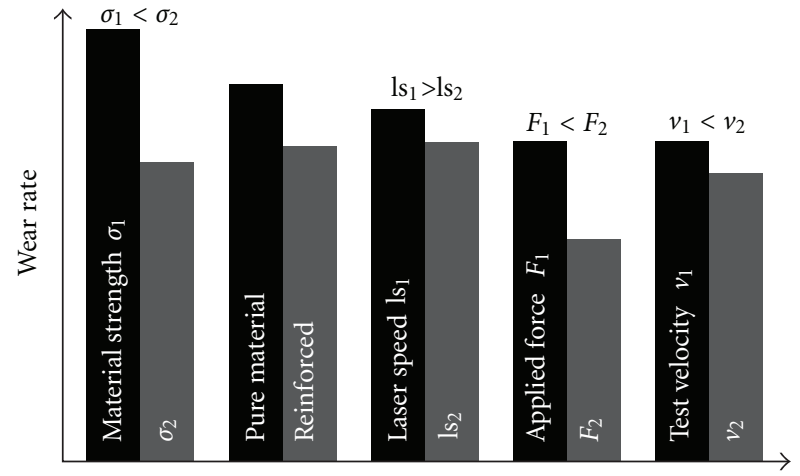

SLS/SLM, process or testing parameter

FIGURE 5: Qualitative impact of several SLS/SLM process and testing parameters on the resulting wear rate.

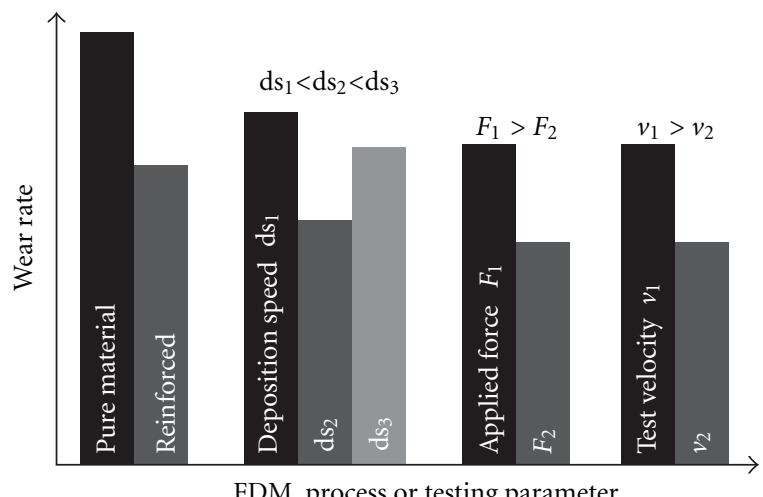

FIGURE 6: Qualitative impact of several FDM process and testing parameters on the resulting wear rate.

It has been implied that the incorporation of ductile materials like copper, which may be considered a lowfriction element, can also increase the wear resistance of iron-based SLS materials [15] while the additions providing insignificant interfacial bonding or poor miscibility of the blended materials may deteriorate the wear-resistance of the composites [38].

When examining the effect of filler materials on a polymeric matrix produced via FDM, it is important to consider that polymers are wear sensitive materials and thus a ceramic reinforcement or metallic fibers may significantly enhance the composite's wear resistance. This has been observed among others, when reinforcing a polycaprolactone (PCL) matrix with hydroxyapatite (HAP). The effect of the ceramic filler material (HAP) exerted a significant effect on the wear progression of the examined biocomposites during dry sliding [19]. Even though the impact of the composition was not linear to the resulting wear progression it was able to enhance the wear resistance of the polymeric matrix by more than $60 \%$. The qualitative effect of the reinforcement on the wear rate of FDM-produced materials is given in Figure 6.

3.3. Effect of SLS/SLM Parameters. SLS and SLM procedures can only be influenced to a certain extent. The laser speed has been documented to hold a noteworthy effect on both coefficient of friction and wear resistance of the produced parts [36]. An increase in fusion speed of the employed powders, consequences in a decrease of coefficient of friction for both, the metallic material and its silicon carbide reinforced matrix. This can be accredited to the reduced densification of the material, as higher laser speed decreases the amount of energy absorbed by the powder, hence resulting in inferior local melting/sintering of the materials $[39,40]$. Reduced density fosters decreased asperity interaction, hence reducing the coefficient of friction during dry sliding, as depicted in Figure 5.

A similar effect is observed when reducing the laser power, as this falls within the prior described concept of reduced densification. An increase of laser power simply marks the transition of SLS to SLM while a further rise would diminish process accuracy due to uncontrolled powder liquefaction.

3.4. Effect of FDM Parameters. It is widely accepted that the alteration of FDM process parameters can significantly affect the mesostructure of the manufactured parts as both, inter- and intralayer bonding is strongly process dependent [18]. In these terms, it may be stated that there exists a complex correlation of FDM process parameters on the wear degeneration of the produced parts (as demonstrated in Figure 6). Several studies have focused on the optimization of RP parameters during FDM [41] but very few have given emphasis on the resulting wear properties of the produced parts. The layer thickness of FDM products, in terms of the employed nozzle diameter, exerts a nonlinear effect on the wear rate of the manufactured parts. This can be attributed to the heat transfer from one layer to another [42]. As the temperature of a newly deposited layer is higher (close to the materials melting point) than the one of the proceeding layer (having already reached its glassy state), heat is transferred from the deposited layer to the substrate one. Depending on the layer thickness, this may act in favor of the products wear resistance as local remelting and thermal diffusion between adjunct filaments results in strengthening of the bonds between the layers [43]. This behavior is observed for large nozzle diameters and becomes even more intense as the diameter increases. An adverse effect can, however, be observed in small layer thicknesses, as the repeated heating and cooling of the polymer or plastic ultimately results in heterogenic temperature gradients within the processed material which lead to residual stresses [44]. These distortions are a dominating phenomenon that worsens the wear development of FDM processed parts up to a certain layer thickness.

The foregoing discussion stretches the importance of the proper heating of the processed material during FDM procedures, an augmentation of which up to a certain temperature will result in better bonding and thus higher wear resistance, while from this point on further increase will inevitably lead to material distortion and inferior wear rates. The geometry of FDM-produced parts, in terms of porosity and scaffold architecture may also affect the components 
wear characteristics as these parameters strongly affect the heat dissipation within the parts structure. This involves a variety of conflicting factors as the complexity of built geometries may differ intensively. It is, however, accepted that high porosity and larger pore size may decrease friction dependent wear, although not notably [18].

3.5. Effect of Testing Conditions. Fretting tests conducted on a series metallic SLS components (Ti6Al4V, CoCrMo, stainless and tool steel, etc.) indicated that an increase of applied load is followed by a decreasing coefficient of friction while promoting higher wear volumes [15]. This behavior can be attributed to shearing of the surface's protuberances due to intensified plastic deformations, thus leading to increased wear rates [36]. It is noteworthy that a comparison between milled and RP tool steel, in terms of wear response, was in favor of latter in all examined load cases.

A similar correlation of applied load and coefficient of friction is encountered during dry sliding [36] although this alteration proved to be comparatively higher al low forces. In contrast to fretting, an increase of load leads to a reduction of wear rates during dry sliding (see Figure 4). This adverse effect tends to fade beyond a certain point, past which the load exhibits only a marginal effect on the coefficient of friction. It is stipulated that this wear response is due to the material composition, as an increase of load rises the temperature in the sliding interface, resulting in the formation of a hard oxide film, acting as a protective layer to the worn material. This may also justify the adverse effect of sliding velocity on the materials wear response in the case of pure Fe [36]. The initial presence of harder Si particles within an iron matrix results in increased wear volumes at higher sliding velocities, as anticipated.

Sliding velocity, however, is considered an important factor during dry sliding especially in the case of polymerbased materials [45], especially in the case of FDM-produced components, which are known to exhibit an intense correlation to applied the testing conditions. This is mainly due to the fact that polymers are far more prone to thermal effects observed during dry sliding/fretting, and it is well known that friction mechanisms are significantly affected by the developing thermal field in the material contact area $[46,47]$. Hence an increase of sliding velocity during friction tests will elevate the temperature of the counter-bodies interface and thus is expected to reveal intense wear progression [48].

The variation of the wear rate of FDM-produced components with the contact load, is virtually linear to the increase of the applied dead weight, a behavior that can be attributed to the activation of the specimen roughness, leading to an increased coefficient of friction, gradually elevating the temperature of the contact interface.

\section{Conclusions}

It is important to presume that wear mechanisms of SLS/SLM-produced parts, subjected to fretting, are mainly composition depended as the examined materials exhibit controversial wear development. Although entrapment of material debris within the sliding interface is observed in all material cases, this can either deteriorate its wear resistance or exert a beneficial effect.

In stainless steels, this "third body effect" unveils an in situ lubricant effect, improving its wear resistance while in harder materials, as tool steels, this inhomogeneous transfer layer is composed of agglomerated debris depreciating their wear endurance.

Dry sliding of metallic SLS materials is less abrasive in terms of wear development. This can be explained by the reduced thermal interaction of the contacting materials as well as the absence of the "third body effect" exhibited by the accumulation of wear debris within the sliding interface.

The foregoing discussion revealed that processing parameters hold indeed a vital role on the produced materials wear resistance, although its composition exerts without a doubt the dominating impact.

The FDM process-dependent wear mechanisms compose a complex phenomenon and even though the effects of various process parameters on the resulting wear mechanisms can be identified, it is nearly impossible to interpret their interactions.

The incurred wear mechanisms during dry sliding (POD tests) are threefold.

(i) Gauging of the polymers surface, which in the case of composite materials may evolve to excavation of the polymeric matrix by the harder reinforcement material.

(ii) Delamination of the polymer or polymeric matrix, especially at high sliding distances where mica-like structures are observed on separate polymeric layers.

(iii) Thermal degeneration of the contact interface, gradually deteriorating the mechanical strength of the sliding surface, thus leading to increased wear progression.

It can be stipulated that decent wear characteristics require the absence of imperfections and distortions, which are associated with the manufacturing temperature. In conclusion, an optimization of the wear resistance of FDM-fabricated parts can be achieved with a factor variation analysis of the process temperature while significant enhancements can be attained solely through proper material reinforcement.

\section{References}

[1] J. P. Kruth, G. Levy, F. Klocke, and T. H. C. Childs, "Consolidation phenomena in laser and powder-bed based layered manufacturing," CIRP Annals-Manufacturing Technology, vol. 56, no. 2, pp. 730-759, 2007.

[2] A. Tsouknidas, S. Maropoulos, S. Savvakis, and N. Michailidis, "FEM assisted evaluation of PMMA and Ti6Al4V as materials for cranioplasty resulting mechanical behaviour and the neurocranial protection," Bio-Medical Materials and Engineering. In press.

[3] M. C. Galetz, T. Uth, M. A. Wimmer, P. Adam, and U. Glatzel, "Determination of the temperature rise within UHMWPE 
tibial components during tribological loading," Acta Biomaterialia, vol. 6, no. 2, pp. 552-562, 2010.

[4] G. Bergmann, F. Graichen, A. Rohlmann, N. Verdonschot, and G. H. van Lenthe, "Frictional heating of total hip implants, part 1: measurements in patients," Journal of Biomechanics, vol. 34, no. 4, pp. 421-428, 2001.

[5] G. Bergmann, F. Graichen, A. Rohlmann, N. Verdonschot, and G. H. van Lenthe, "Frictional heating of total hip implants. Part 2: finite element study," Journal of Biomechanics, vol. 34, no. 4, pp. 429-435, 2001.

[6] S. He, S. Cho, and R. Singh, "Prediction of dynamic friction forces in spur gears using alternate sliding friction formulations," Journal of Sound and Vibration, vol. 309, no. 3-5, pp. 843-851, 2008.

[7] T. Cousseau, B. Graça, A. Campos, and J. Seabra, "Friction torque in grease lubricated thrust ball bearings," Tribology International, vol. 44, no. 5, pp. 523-531, 2011.

[8] X. Q. Yu, S. He, and R. L. Cai, "Frictional characteristics of mechanical seals with a laser-textured seal face," Journal of Materials Processing Technology, vol. 129, no. 1-3, pp. 463-466, 2002.

[9] C. M. Cheah, C. K. Chua, C. W. Lee, C. Feng, and K. Totong, "Rapid prototyping and tooling techniques: a review of applications for rapid investment casting," International Journal of Advanced Manufacturing Technology, vol. 25, no. 34, pp. 308-320, 2005.

[10] G. N. Levy, R. Schindel, and J. P. Kruth, "Rapid manufacturing and rapid tooling with layer manufacturing (LM) technologies, state of the art and future perspectives," CIRP AnnalsManufacturing Technology, vol. 52, no. 2, pp. 589-609, 2003.

[11] S. M. Peltola, F. P. W. Melchels, D. W. Grijpma, and M. Kellomäki, "A review of rapid prototyping techniques for tissue engineering purposes," Annals of Medicine, vol. 40, no. 4, pp. 268-280, 2008.

[12] J. Winder and R. Bibb, "Medical rapid prototyping technologies: state of the art and current limitations for application in oral and maxillofacial surgery," Journal of Oral and Maxillofacial Surgery, vol. 63, no. 7, pp. 1006-1015, 2005.

[13] E. Sachlos and J. T. Czernuszka, "Making tissue engineering scaffolds work. Review on the application ofsolid freeform fabrication technology to the production of tissue engineering scaffolds," European Cells and Materials, vol. 5, pp. 29-40, 2003.

[14] J. M. Williams, A. Adewunmi, R. M. Schek et al., "Bone tissue engineering using polycaprolactone scaffolds fabricated via selective laser sintering," Biomaterials, vol. 26, no. 23, pp. 4817-4827, 2005.

[15] S. Kumar and J. P. Kruth, "Wear performance of SLS/SLM materials," Advanced Engineering Materials, vol. 10, no. 8, pp. $1-4,2008$.

[16] A. Rosochowski and A. Matuszak, "Rapid tooling: the state of the art," Journal of Materials Processing Technology, vol. 106, no. 1-3, pp. 191-198, 2000.

[17] J. P. Li, J. R. de Wijn, C. A. van Blitterswijk, and K. de Groot, "The effect of scaffold architecture on properties of direct 3D fiber deposition of porous Ti6Al4V for orthopedic implants," Journal of Biomedical Materials Research-Part A, vol. 92, no. 1, pp. 33-42, 2010.

[18] A. Equbal, A. K. Sood, V. Toppo, R. K. Ohdar, and S. S. Mahapatra, "Prediction and analysis of sliding wear performance of fused deposition modelling-processed ABS plastic parts," Proceedings of the Institution of Mechanical Engineers Part J, vol. 224, no. 12, pp. 1261-1271, 2010.
[19] A. Tsouknidas, D. Kountouras, S. Maropoulos, N. Kiratzis, and N. Michalilidis, "Tribological, mechanical and physical characterization of hydroxyapatite/polycarpolactone biocomposites," Journal of the Balkan Tribological Association. In press.

[20] S. Kumar, J. P. Kurth, J. van Humbeeck, and A. Voet, "A study of degeneration of laser sintered moulds using wear tests," Rapid Prototyping Journal, vol. 15, no. 2, pp. 104-110, 2009.

[21] R. C. Bill, "Review of factors that influence fretting wear," in Materials Evaluation Under Fretting Conditions, ASTM STP 780, S. R. Brown, Ed., pp. 165-181, ASTM, Philadelphia, Pa, USA, 1982.

[22] R. B. Waterhouse, "Fretting fatigue," International Journal of Fatigue, vol. 37, no. 2, pp. 77-97, 1992.

[23] M. Niinomi, "Mechanical biocompatibilities of titanium alloys for biomedical applications," Journal of the Mechanical Behavior of Biomedical Materials, vol. 1, no. 1, pp. 30-42, 2008.

[24] P. Schaaff, "The role of fretting damage in total hip arthroplasty with modular design hip joints -evaluation of retrieval studies and experimental simulation methods," Journal of Applied Biomaterials \& Biomechanics, vol. 2, no. 3, pp. 121135, 2004.

[25] Y. Berthier, L. Vincent, and M. Godet, "Fretting fatigue and fretting wear," Tribology International, vol. 22, no. 4, pp. 235242, 1989.

[26] S. Fouvry, P. Kapsa, and L. Vincent, "Fretting-wear and fretting-fatigue: relation through a mapping concept," in Fretting Fatigue: Current Technology and Practices, ASTM STP 1367, D. W. Hoeppner, V. Chandrasekaran, and C. B. Elliott, Eds., pp. 49-64, ASTM, West Conshohocken, Pa, USA, 2000.

[27] V. Chandrasekaran, W. L. Sauer, A. M. Taylor, and D. W. Hoeppner, "Evaluation of the fretting corrosion behavior of the proximal pad taper of a modular hip design," Wear, vol. 231, no. 1, pp. 54-64, 1999.

[28] M. Varenberg, G. Halperin, and I. Etsion, "Different aspects of the role of wear debris in fretting wear," Wear, vol. 252, no. 11-12, pp. 902-910, 2002.

[29] E. Rabinowicz, Compatibility Criteria for Sliding Metals in Friction and Lubrication in Metal Processing, ASME, New York, NY, USA, 1996.

[30] F. P. Bowden and D. Tabor, "The influence of surface finish on the friction and deformation of surfaces in properties of metallic surfaces," Journal Institute of Metals, pp. 197-212, 1953.

[31] ASTM G99-04: Standard Test Method for Wear Testing with a Pin-on-Disk Apparatus, ASTM International.

[32] T. C. Ovaert and H. S. Cheng, "Counterface topographical effects on the wear of polyetheretherketone and a polyetheretherketone-carbon fiber composite," Wear, vol. 150, no. 1-2, pp. 275-287, 1991.

[33] D. Dowson, S. Taheri, and N. C. Wallbridge, "The role of counterface imperfections in the wear of polyethylene," Wear, vol. 119, no. 3, pp. 277-293, 1987.

[34] P. H. Chong, H. C. Man, and T. M. Yue, "Microstructure and wear properties of laser surface-cladded Mo-WC MMC on AA6061 aluminum alloy," Surface and Coatings Technology, vol. 145, no. 1-3, pp. 51-59, 2001.

[35] K. Murali, A. N. Chatterjee, P. Saha et al., "Direct selective laser sintering of iron-graphite powder mixture," Journal of Materials Processing Technology, vol. 136, no. 1-3, pp. 179-185, 2003.

[36] C. S. Ramesh and C. K. Srinivas, "Friction and wear behavior of laser-sintered iron-silicon carbide composites," Journal of 
Materials Processing Technology, vol. 209, no. 14, pp. 54295436, 2009.

[37] C. S. Ramesh, S. K. Seshadri, and K. J. L. Iyer, "A survey of aspects of wear of metals," Indian Journal of Technology, vol. 29, no. 4, pp. 179-185, 1991.

[38] N. Saka and D. P. Karalekas, "Friction and wear of particle reinforced metal ceramic composites," in Proceedings of the Conference on Wear of Materials, pp. 784-793, ASME, New York, NY, USA, 1985.

[39] A. Simchi, F. Petzoldt, and H. Pohl, "Direct metal laser sintering: material considerations and mechanisms of particle bonding," International Journal of Powder Metallurgy, vol. 37, no. 2, pp. 49-61, 2001.

[40] A. Simchi and H. Pohl, "Effects of laser sintering processing parameters on the microstructure and densification of iron powder," Materials Science and Engineering A, vol. 359, no. 1-2, pp. 119-128, 2003.

[41] B. H. Lee, J. Abdullah, and Z. A. Khan, "Optimization of rapid prototyping parameters for production of flexible ABS object," Journal of Materials Processing Technology, vol. 169, no. 1, pp. 54-61, 2005.

[42] A. K. Sood, R. K. Ohdar, and S. S. Mahapatra, "Parametric appraisal of fused deposition modelling process using the grey Taguchi method," Proceedings of the Institution of Mechanical Engineers Part J, vol. 224, no. B1, pp. 135-145, 2010.

[43] Q. Sun, G. M. Rizvi, C. T. Bellehumeur, and P. Gu, "Effect of processing conditions on the bonding quality of FDM polymer filaments," Rapid Prototyping Journal, vol. 14, no. 2, pp. 72-80, 2008.

[44] A. K. Sood, R. K. Ohdar, and S. S. Mahapatra, "Parametric appraisal of mechanical property of fused deposition modelling processed parts," Materials and Design, vol. 31, no. 1, pp. 287-295, 2010.

[45] K. Friedrich, Z. Zhang, and P. Klein, "Wear of polymer composites," Wear Material Mechanisms and Practice, pp. 269287, 2005.

[46] G. Wröbel and M. Szymiczek, "Influence of temperature on friction coefficient of low density polyethylene," Journal of Achievements in Materials and Manufacturing Engineering, vol. 28, no. 1, pp. 31-34, 2008.

[47] D. Shakhvorostov, K. Pöhlmann, and M. Scherge, "An energetic approach to friction, wear and temperature," Wear, vol. 257, no. 1-2, pp. 124-130, 2004.

[48] T. Nakahara, S. Momozono, and A. O. Rui, "Effect of surface temperature rise on friction characteristics for sliding speed under unlubricated condition," Proceedings of the Institution of Mechanical Engineers Part J, vol. 224, no. 3, pp. 271-278, 2010. 

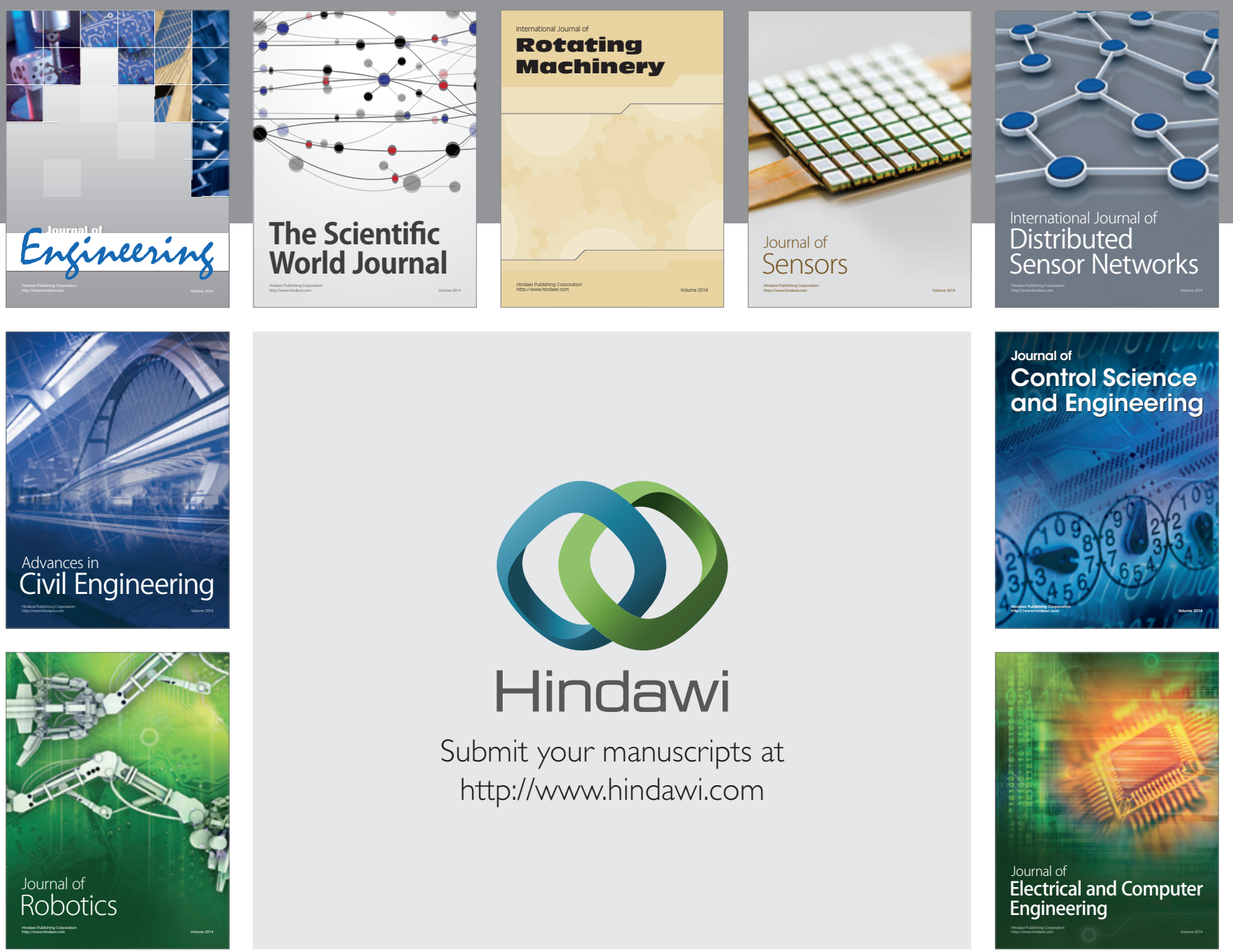

Submit your manuscripts at

http://www.hindawi.com
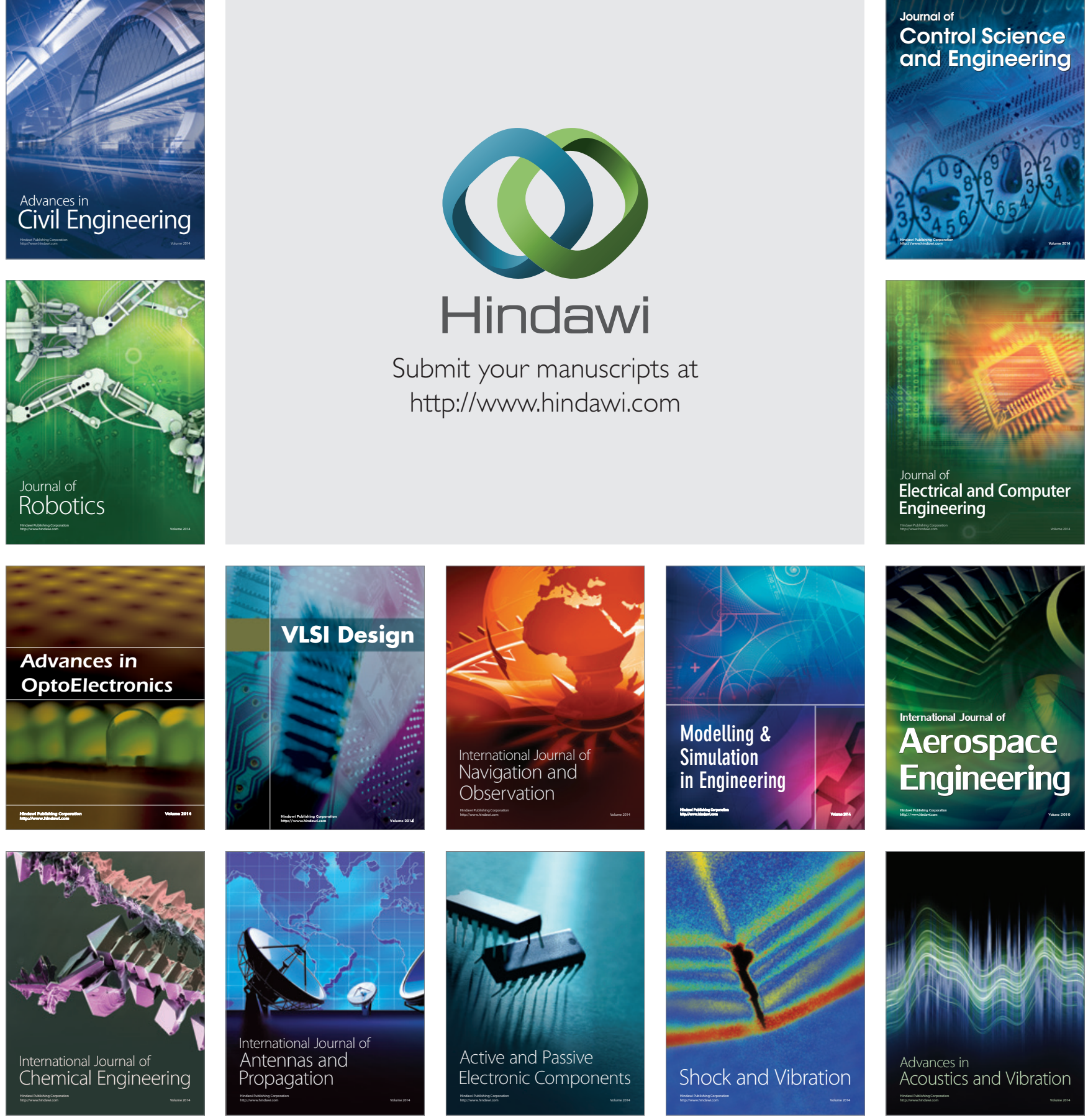